\title{
Task-driven Instructional Design on the Development of Language Ability
}

\author{
Guoyou Ma \\ School of English Education \\ Xi'an International Studies University \\ Xi'an, China 710128
}

\author{
Sheming Qu \\ School of English Education \\ Xi'an International Studies University \\ Xi'an, China 710128
}

\begin{abstract}
Language ability constitutes the basic element of the core literacy of English subjects and is one of the specific goals of teaching on English curriculum. Improving students' language ability implies the improvement of students' cultural awareness, thinking quality and learning ability, which helps to expand students' international vision and mode of thinking. Task-driven instructional design on the development of language ability requires teachers to drive students to ingest, process and produce language information through scientific design of learning tasks, effective implementation of task teaching, and comprehensive evaluation of students' language ability development effects, and ultimately improve language development.
\end{abstract}

Keywords-language ability; task-driven; instructional design

\section{INTRODUCTION}

National English Curriculum Standards for Common Senior High School (2017) (hereinafter referred to as the 2017 new curriculum standards) identifies the development and development of students' key competencies as the specific goal of the teaching of ordinary high school English curriculum. The key competencies of English subjects consist of language ability, cultural awareness, thinking quality and learning ability. The language ability constitutes the basic element of the key competencies of English subjects [1]. What is language ability? What is the language ability? How to develop language skills? These questions will be the core topic of future high school English subject teaching research.

\section{LANGUAGE ABILITY}

The academia has proposed the following views on the definition and composition of language ability. In Canale and Swains' (1980) thesis "Theoretical bases of communicative approaches to second language teaching and testing", it was thought that language ability is the fusion of grammatical ability, social language ability and strategic ability [2]. In "From communicative competence to communicative language pedagogy", Canale(1983) thought language ability consists of discourse ability, grammatical ability, social language ability, and strategic ability [3]; Bachman and Palmer (1996) argue in the Language Testing in Practice: Designing and Developing Useful Language Tests that language ability includes linguistic knowledge, emotional representation, individual characteristics, topic knowledge, and strategic abilities [4]. Celce-Murcia Drnyei and Thurrell (1995) also proposed a five-dimensional view of language competence in the book "Communicative competence: A pedagogically motivated model with content specifications", namely discourse ability, action ability, sociocultural ability, language ability, and strategic ability, etc [5]. Bachman (1990) regards language ability/knowledge, strategic ability, and psychophysiological ability as the basic components of language ability in Fundamental Consideration in Language Testing [6]. Cai Bing (2013) regards language knowledge, application, level, and skills as the basic structure of language ability in the article "What is "language ability?" [7] Liu Zhen and Mei Deming (2015) proposed a bi-gram model of language ability, namely human ability and instrumental ability [8]. In addition, there are CEFR models such as general language skills (such as declarative knowledge, skills, survivability and learning ability) [9] and communicative language skills (such as language skills, social language skills, pragmatic competence) [10].

In a narrow sense, language ability refers to basic language skills such as listening, speaking, reading, writing, and reading; in a broad sense, language ability refers to the organic fusion of various abilities related to language use. These include language basic skills, awareness and cognition of language and language learning, ability to understand and use linguistic knowledge, communicative identity awareness, the ability to use language knowledge to construct and express meaning, and ability to understand oral and written discourse of various subjects, etc. The 2017 new curriculum standards defines language ability as "the ability to understand and express meaning in the way of listening, speaking, reading, reading, writing, etc., and the language awareness and sense of language formed in the process of learning and using language in the social context." [1]

The development of English language ability of Chinese students in the Chinese environment is a process of mutual fusion of complex psychological cognition and social interaction. First of all, students must master a large number of English language and Chinese and foreign cultural knowledge. Among them, English knowledge includes speech, vocabulary, grammar, discourse and pragmatics. Chinese and foreign cultural knowledge includes material 
culture and spiritual culture: material culture includes food culture, costume culture, architectural culture, transportation culture, invention and creation, spiritual culture includes philosophy, science, education, history, literature, art, values, moral cultivation, aesthetic taste, social conventions and customs [1], This knowledge is the cornerstone of students' cross-cultural communication. Secondly, students need to practice language through question-and-answer, debate, discussion and presentation in the real language learning environment created by teachers. This is the basic means for students to construct English language cognitive structure and develop language communication rules. Finally, students need to use language through oral and written expression. Drawing on the research results of language ability at home and abroad, based on the definition of language ability of 2017 new curriculum standards, combined with the practice of senior high school English teaching, this study defines the language ability of English key competencies as four dimensions: cognitive ability, functional ability, strategic ability and social ability. Among them, cognitive ability refers to the learner's ability to grasp and master the language knowledge. Functional ability refers to the learner's ability to develop language skills. Strategic ability refers to the learner's ability to acquire language information and use language knowledge, such as ability to use network information resource, social ability refers to the learner's ability to think, communicate, cooperate, cross-cultural, and solve problems. The main place for Chinese students to improve their English language ability is the classroom. The scientific combination of teachers' various elements of classroom teaching, such as teaching objectives, content, atmosphere, methods, activities, evaluations, etc, affects the systemic and completeness of students' understanding of English structure to a certain extent, and determines flexibility and automation of students' use of English language. As for the learner's language ability development strategy, the research conclusions include: contacting with a large amount oral and written discourse, using English, understanding the meaning of the discourse, and comprehending the deep connotation of the discourse, with unit teaching as the core, designing a holistic language learning activity that integrates language skills such as listening, speaking, reading and writing, establishing students' positive learning orientation, creating appropriate and appropriate learning situations, and playing the intermediary role of teachers to transform students' learning styles, implementing task-based language teaching activities [11]. Teachers should design a teaching model that conforms to the students' thinking mode, that is, content teaching guided by the design theme making the teaching design contextualized, problematic and active [12]. Based on the needs of students, organize teaching, learn to communicate, and pay attention to cultural understanding and expression [13]. Create a good foreign language environment and create more opportunities for speech practice [14]. Compiled the task-based teaching content into the textbook to realize the collaborative training of language and thinking ability [15]. These teaching strategies are limited to theoretical elaboration and lack of instructional design and practice. How to promote the development of students' English ability by designing classroom teaching, the research results are relatively lacking. This study uses task-driven teaching theory to explore the practical path of English ability development from the perspective of instructional design.

\section{TASK-DRIVEN TEACHING}

Task-driven Teaching believes that learning is not only the process of transfer and delivery of knowledge from outside to inside, but also the process by which learners actively construct knowledge. Teachers should carry out teaching through scientific design, effective implementation and comprehensive evaluation of learning tasks to drive teachers' teaching and students' study, create a real learning environment as a means, design real learning tasks as a medium, and give learners the initiative and encourage learners exploring independently or collaboratively, integrate old and new knowledge, enrich the knowledge structure, and develop practical skills. Learners should learn on the basis of tasks or problems, and maintain their interest in learning and stimulate their motivation by learning problems or completing tasks.

Task-driven teaching has changed the teaching situation in which teachers used to dominate the classroom and learners passively responded to the classroom. It created a new learning model based on the learning method of learning, using teaching to promote student learning, active participation of learners, independent collaboration, and exploration and innovation. Learners focus on learning tasks, driven by strong learning motivation, integrate learning resources, explore independently, and collaborate. The teacher transforms the indoctrinated teaching concept into a multi-dimensional interactive teaching concept based on the students aiming at completing tasks, promotes the learner to deeply understand the learning task and actively design the task completion plan. Practice has proved that task-driven teaching can encourage learners to actively participate in learning activities, and achieve the goal of language ability development through participation in learning activities.

Task-driven teaching advocates teachers as the mainstay and students as the main body. The teacher's dominance is embodied in the design of learning tasks, expounding the task completion goals, and evaluating the task completion results; the student's subjectivity is reflected in the completion, presentation, and improvement of the learning tasks. The teaching implementation links are: (1) Analyzing the teaching objectives: the teacher determines the teaching objectives and refines the target sequence. (2) Designing learning tasks: select issues closely related to the current learning theme as the central content of learning, design related learning tasks; present learning tasks, create task completion scenarios, and guide learners into learning situations. (3) Determining the task objectives: the task objectives are macro and micro, the macro objectives are generalized, and the micro objectives are specific. (4) Implementation of task learning: students take tasks as the core, complete tasks by independent or cooperative means, and present task completion results. (5) Evaluation task completion effect: the evaluation content focuses on the process and result of the student completing the task. 


\section{TEACHING DESIGN}

The practical operation procedure of language ability development based on task-driven teaching is to scientifically design teaching objectives, effectively implement task teaching, and comprehensively evaluate the task completion effect. The following is an example interpretation of Computers unit teaching.

\section{A. Scientifically Designing the Teaching Objectives}

Teaching objectives include cognitive, functional, strategic, and social abilities.

- Cognitive ability: students acknowledge vocabularies, such as simplify, sum, operator, logically, technological revolution, artificial intelligence, solve, totally, network, application, finance, mobile, rocket, explore, goal, etc., and the passive voice of present perfect of these vocabularies.

- Functional ability: that can comprehensively use the comprehensive skills of listening and comprehensive skills of speaking, reading and writing.

- Strategic ability: Can use a variety of resources to query relevant knowledge, consolidate and expand the teaching content.

- Social ability: can effectively think and cooperate to solve learning problems.

\section{B. Effectively Implementing the Teaching Process}

This includes designing and presenting learning tasks, refining learning task objectives, and implementing learning tasks.

1) Designing and presenting learning tasks: According to the teaching objectives, the teacher designs and presents the following learning tasks for the students:

- Cognitive learning: vocabulary and grammatical cognitive tasks: students read the text independently, complete the exercises of $1,2,3$ in the Learning about language and the exercises of 1, 2, 3 in discovering useful structures.

- Functional development: Complete Listening and speaking in Using Language, do exercises 1, 2, 3, 4; reading, speaking and writing in Using Language, complete exercises $1,2,3$.

- Strategy development: Two students are a group, one of whom is a journalist and the other is a computer expert. They consult knowledge about computer history and application, carrying out pairing activities.

- Social ability: Students can find their opponents to conduct debates, with the topic of Computer can bring about more problems for our human beings in the future and Computer can bring about more convenience for our human beings.
2) Refining the objectives of learning tasks:

- Acknowledge learning objectives: use vocabularies of the new curriculum standards to grasp the structure, usage and conversion strategies of the passive voice of present perfect.

- Functional development objectives: can enumerate the IT form, understand the meaning of the text, write the text theme; can apply the functional sentence patterns in the text, discuss the advantages and disadvantages of the four information technology carriers; can understand the text content; can apply the text knowledge and describe self-designed robots, both verbally and in writing.

- Strategy development goal: carry out two-person pairing activities, use extracurricular learning resources to access knowledge and expand learning content.

- Social ability goal: can debate on computer topics.

\section{3) Implementing task learning:}

a) Language knowledge learning: Students present the words in Exercise 1, and teachers evaluate; students quickly browse the essays in exercises 2 and answer questions: Who is the character in this passage? What is special about this character? Students will string together the words, write a paragraph in the short text; students quickly read the essays in practice 3 , master the general idea, pay attention to the use of temporal expression in the short text, follow the example on the right, compose the story, doing the simulate writing exercises.

Students follow the example of exercise 1, find out similar sentences in the text and present them, analyze the similarities and differences of sentence structure, understand the meaning of sentences, and the teachers explain them; students present the answers of exercise 2, and teacher evaluate them; students read poems in practice 3 silently, and experience the usage of passive voice of present perfect, process poetry information, find accurate sentences, filling in different columns of the table; teachers guide students to understand the derogatory sense of the first paragraph of poetry, the commendatory sense of the second paragraph, and students write poetry imitatively.

b) Language skills development: Comprehensive development of listening and speaking skills: students listen to the recordings, summarize the general meaning; listen again, fill out the forms, grasp the details; recall the functional sentences in the lesson and previous texts that express opinions, state the reasons, make decisions, use these patterns to express themselves' viewpoints; list the four advantages and disadvantages of information technology provided in listening materials, write opinions, share in group, present in class, and teachers evaluate them.

Comprehensive skills development in reading, speaking and writing: students look at pictures and article titles, guess the meaning of the article, and answer the following questions: What can you see in the picture? What are they 
doing? What do you think the word android mean? Students read the text silently and answer questions: Who is talking in the passage? Is Andy a real person? What does Andy look like? What is Andy's job in the football team? Which competition has Andy been to? Did Andy's team win the Seattle competition? What happened? Who helps Andy move in the football competition? According to the requirements of exercise 1, the students complete the Andy information file; the teacher lists the words in the text, and the students interpret them. Students imagine, design robots, model the Andy information files, write robot information files with phrases; students read the short texts in exercise 3 and draw typical sentence patterns, such as I would like to have an android that___; This means that it should ___ it should also__ ; In that way_I don't mind__ but it must be able to... Students use these sentence patterns to carry out imitation activities and describe their own robots. Teachers evaluate the punctuation, wording, creativity, grammar, etc., and summarize the students' writing errors and analyze and correct them.

c) Learning strategy: Students follow the teacher's requirements, collect computer history, use knowledge, and sub-items are listed in outline form; 2 people are a group to conduct interview activities. The teacher records the student's language errors, analyzes the causes, and proposes solutions; the teacher selects representative group to perform, and other students watch and learn.

d) Social ability: The teacher designs the topic of debate. The students form the pros and cons. Each party determines the debater and the concluding person, each performs their duties, collects the materials, and records them in an outline form. The same debate group will communicate first, be familiar with the content of the debate, and prepare for the debate. Teachers and debate groups review this unit's statement of sentence patterns so that students can apply what they have learned. After the debate, the students completed the essay with the theme of the advantages and disadvantages of the computer.

e) Comprehensively evaluateing the effect of students' English language ability development: This stage is a comprehensive evaluation of the students' development in the four dimensions of language ability, involving evaluation content, means, and subjects. Cognitive ability development evaluation covers two modules of grammar and vocabulary. The grammar evaluation should be based on the "form-meaning-use" three-dimensional dynamic grammar concept, focusing on the form, meaning and use evaluation of the current completion type, "form" refers to the structure and form of passive voice of present perfect, "meaning" refers to the meaning of its expression, and "use" refers to the accuracy and appropriateness of its use in oral and written contexts; vocabulary evaluation focuses on the sound, shape, meaning and usage of words, "sound" involves accent, intonation, rhythm, suspension, continuous reading, blasting, assimilation, etc. "shape" refers to the form and structure of words, such as roots, affixes, etc. "meaning" refers to the original meaning and extended meaning of the word, customary English, synonymy and antonymy, etc. "usage" involves the learner through language activities such as listening, speaking, reading, watching and writing. Cognitive ability evaluation is mainly based on tests, and the evaluation subjects are teachers and students. Functional ability evaluation mainly depends on whether students can use the comprehensive skills of listening, speaking, reading and writing. The evaluation methods are mainly based on testing and observation. The evaluation subjects are teachers and students. Strategic competency assessment focuses on the ability of learners to use a variety of resources to query relevant knowledge, such as the ability to use network resources, library resources, peer learning resources, and so on. The evaluation of social ability involves critical thinking ability and the ability to solve learning problems cooperatively. The critical thinking ability focuses on students' ability of analysis, synthesis, judgment and reasoning. The evaluation methods mainly include observation method, reflection method, questionnaire method, etc. The evaluation subjects are teachers and students.

\section{CONCLUSION}

One of the four key competencies of English subjects is language ability. Developing students' language ability is one of the specific goals of English curriculum teaching. Based on the task-driven teaching theory, this study explores the practical path of students' language ability development from the perspective of classroom instruction design. This research can not only provide practical reference for English teachers to carry out English teaching, but also provide guidance for learners to improve their language abilities.

\section{REFERENCES}

[1] Ministry of Education of the People's Republic of China. National English Curriculum Standards for Common Senior High School (2017) [M]. Beijing: People's Education Press, 2017. ( in Chinese)

[2] Canale, M. \& M. Swain. Theoretical bases of communicative approaches to second language teaching and testing [J]. Applied Linguistics, 1980( 1): 1-47.

[3] Canale, M. From communicative competence to communicative language pedagogy [A]. In J. Richards \& R. Schmidt (eds.). Language and Communication[C] London: Longman,1983.

[4] Bachman, L. \& A. Palmer. Language Testing in Practice: Designing and Developing Useful Language Tests [M]. Oxford: Oxford University Press, 1996.

[5] Celce-Murcia, M.Z. Drnyei \& S. Thurrell. Communicative competence: A pedagogically motivated model with content specifications[J]. Issues in Applied Linguistics, 1995 (2): 5-35.

[6] Bachman, L. Fundamental Consideration in Language Testing[M]. Oxford: Oxford University Press, 1990.

[7] Cai Bing. What is "language ability"? [J]. Linguistic Sciences, 2013 (6): 612-617. ( in Chinese)

[8] Liu Zhen, Mei Deming. What kind of English ability is needed for college students in China [J] Journal of Xi'an International Studies University, 2015(3): 65-68. ( in Chinese)

[9] Goullier, F.Tools for Language Teaching: Common European Framework and Portfolio [M]. Strasbourg: Council of Europe, 2008.

[10] Council of Europe (Co E). Common European Framework of Reference for Languages: Learning, Teaching, Assessment ( CEFR) 
[M]. Strasbourg: Council of Europe/Cambridge: Cambridge University Press, 2001.

[11] Liu Daoyi, Li Jingchun, Huang Yuanzhen, etc. English Language Literacy: Cultivation of English Language Ability [J]. English Language Learning (Teacher Edition), 2015(11): 16-19. ( in Chinese)

[12] Wang Qiang. From the Comprehensive Language Application Ability to the Core Competence of English Discipline - The New Challenge of High School English Curriculum Reform[J]. English Teachers, 2015(16): 6-7. ( in Chinese)

[13] Chen Youlin. On the Cultivation of Foreign Language Ability[J]. Journal of Central China Normal University, 2000(1): 113-118. ( in Chinese)

[14] Sun Chengrong. Research on Foreign Language Environment and Foreign Language Ability Acquisition Efficiency [J]. Shandong Foreign Languages Teaching Journal, 2004 (6): 41-43. ( in Chinese)

[15] Sui Xiaobing, Zhou Tianhao. The R\&D of Foreign Language Teaching Textbook and the Cultivation of Students' Foreign Language Ability - Based on the Analysis and Discussion of the Main Foreign Language Teaching Textbook in Colleges and Universities in China [J]. Media in Foreign Language Instruction, 2012(11): 52-5. ( in Chinese) 